\title{
AS FAZENDAS DISTÓPICAS DE GEORGE ORWELL E CHICO BUARQUE: TRANSFIGURAÇÕES FICCIONAIS DO AUTORITARISMO
}

\author{
Ramiro Giroldo \\ Rebeca Cacho de Soura $a^{* *}$
}

\begin{abstract}
RESUMO: O texto tem como objetivo discutir de que forma as noções de utopia e distopia podem ser ficcionalmente transfiguradas em diferentes contextos, bem como as mudanças dessas noções de acordo com cada tempo e lugar. Seus objetos são duas obras de momentos e lugares diferentes: $A$ Revolução dos Bichos, de George Orwell (1945), e Faz̧enda Modelo, de Chico Buarque (1976). Nelas, respectivamente, é possível perceber a alusão ao período da Revolução Russa e ao período ditatorial no Brasil. A análise busca discutir a relação intertextual, abordando: os títulos semelhantes, os ambientes ficcionais de exploração animal e a crítica social que se encontra no cerne da discussão de ambas as obras em seus quadros imaginários utópicos/distópicos. Fornecerão embasamento Ernst Bloch (2005), acerca da utopia, Eric Hobsbawn (1995), sobre a História, e Mary Elizabeth Ginway (2005), no que cabe à leitura comparada das obras em pauta.
\end{abstract}

PALAVRAS-CHAVE: Utopia; Distopia; Revolução dos Bichos; Fazenda Modelo; Autoritarismo.

A primeira aproximação possível, por ser a mais evidente, entre as obras $A$ Revolução dos Bichos (1945), de George Orwell, e Faz̧enda Modelo (1974), de Chico Buarque, é a semelhança do título, principalmente se for feita uma tradução direta do título da obra de

\footnotetext{
* Doutor em Literatura Brasileira pela Universidade de São Paulo (Usp). Professor Adjunto "A" da Universidade Federal de Mato Grosso do Sul (UFMS).

${ }^{* *}$ Mestranda em Estudos de Linguagens pela Universidade Federal de Mato Grosso do Sul (UFMS).
} 
Orwell - Animal Farm, "Fazenda Animal”. Além de ambas lidarem com histórias de fantasia, nas quais as normas da realidade palpável são violadas, ambas são ambientadas em espaços similares, nos quais os animais são explorados irrestritamente pelo homem.

Como esperado, dadas as particularidades constitutivas de cada autor, bem como do contexto em que eles se viam imersos no momento de produção, há notáveis distinções entre as obras. Se as parecenças nos servem de um primeiro ponto de apoio, nas diferenças é que residem as especificidades a serem descobertas e exploradas. Elas, afinal, permitirão observar como pode mudar em diferentes tempos e lugares a noção de utopia - e também observar de que forma podem mudar o feitio da esperança, da frustração e do horror distópico que às vezes sucede os malfadados projetos distópicos.

O romance de Orwell é ambientado dentro de uma granja, a princípio denominada Granja do Solar - local em que Sr. Jones toma conta dos animais. Tudo parece correr bem para ele, até o Velho Major, um ancião da granja, ter um atípico sonho. Uma epifania que o leva a pedir que os animais não mais se submetam à servidão, conclamando-os a se libertar da escravidão imposta pelos humanos.

Trata-se de uma epifania capaz de sugerir possíveis desvios no aparentemente prédeterminado caminho histórico. Porta a esperança utópica e é sua fomentadora - desde que a utopia seja compreendida, como quer Ernst Bloch, como a "expectativa, esperança e intenção voltadas para a possibilidade que ainda não veio a ser” (BLOCH, 2005, p. 17). A expectativa de que as coisas na granja pudessem ser diferentes - e melhores - motiva uma mudança que tem a intenção de substituir o processo de abuso e exploração por políticas igualitárias e justas. A esperança se opõe, notemos, a uma conjuntura marcadamente negativa. Distópica, é uma conjuntura que combate a própria esperança, o próprio horizonte utópico. Característico da distopia, a faceta negativa da utopia, é negar desta a mera possibilidade - ou, melhor dizer, tentar infrutiferamente negar.

A utopia, contudo, prevalece em seu intuito de modificar o mundo, diametralmente oposta ao sentido a ela atribuído pelo senso comum. Nas palavras de Ernst Bloch, o sentido a ser perseguido de utopia é, por assim dizer, "realista", distinto do sentido a ela 
comumente atribuído. Se o sentido habitual remete a um sonho desvinculado das preocupações reais, Bloch fala de outro sentido, "que de modo algum é necessariamente abstrato ou alheio ao mundo, mas sim inteiramente voltado para o mundo: o sentido de ultrapassar o curso natural dos acontecimentos" (BLOCH, 2005, p. 22).

Ultrapassar tal curso é o que anseia o Velho Major: superar o estado vigente e modificar a ordem que parece impossível de ser alterada. Após seu falecimento, a influência das ideias utópicas continua a agir sobre a granja. Os animais decidem ouvir o conselho de seu ancião e mediar uma "revolução". A intenção é adquirir o poder de escolha e organização na granja, bem como total igualdade - o que encerraria de vez a exploração exercida sobre todos os animais. Há violência no momento da revolta, pois o curso corrente dos acontecimentos aparentemente não seria alterado com uma intervenção cândida:

Uma das vacas rebentou a chifradas a porta do celeiro, e os bichos avançaram sobre as tulhas. Nesse momento, Jones acordou. Num átimo, ele e seus quatro peões estavam no celeiro com os chicotes na mão, batendo a torto e a direito. Isso ultrapassou tudo quanto os animais mais famintos pudessem suportar. De comum acordo, muito embora nada fosse planejado, lançaram-se sobre seus verdugos. Jones e os homens viram-se de repente marrados e escoiceados de todo lado. A situação fugira do controle. Nunca tinham visto os animais daquele jeito, e a súbita revolta de criaturas que eles estavam acostumados a surrar e maltratar a vontade os encheu de pavor. Em poucos instantes largaram de defender-se e deram o fora (ORWELL, 2007, p. 21).

A revolução se inicia dessa forma, com a expulsão dos humanos e a consequente retirada do poder das mãos do Sr. Jones. Após o sucesso do plano, a granja passa a se chamar Granja dos Bichos. Quem lidera todo o movimento, a pedido do Velho Major, são os dois porcos: Bola de Neve e Napoleão. Eles iniciam seu governo criando políticas de igualdade entre todos os animais, sem distinções. Parece o surgimento de uma utopia: as ideias propagadas pelo Velho Major aparentemente estão sendo postas em prática, e o horizonte utópico foi alcançado. Fissuras no projeto da utopia, contudo, logo se deixam entrever. 
Os líderes, por serem os "pensantes” da granja, se impõem de um modo inesperado, reescrevendo algumas regras à revelia dos outros animais. Dessa forma, o cenário utópico de igualdade que era almejado dentro da granja, no início do cenário distópico de exploração dos animais, começa gradualmente a se converter novamente em uma distopia - visto que, na nova conjuntura, a segregação entre os animais toma cada vez mais força. A dinâmica entre insatisfação e anseio por melhoras, em torno da qual se movimentam os conceitos de utopia e distopia, é posta em cena: apenas quando o indesejável é apreendido criticamente, é possível formular uma alternativa utópica capaz de superar o curso dos acontecimentos e as deficiências do real.

Outro fator que corrobora para a nova inclinação distópica é o momento em que Napoleão aplica um golpe que retira Bola de Neve da granja, fazendo assim com que todo o poder se concentre em suas mãos. A promessa de igualdade, diante de tal ação, se mostra enganosa: a granja está nas mãos de Napoleão e apenas dele, e seus interesses parecem ter passado a ser a concentração de mais e mais poder.

Cabe lembrar, não sem o temor de efetuar uma transição brusca, o contexto histórico de produção da obra de George Orwell e as possíveis analogias entre a traição de Napoleão e a traição soviética para com os preceitos da Revolução Russa. Para lidar com o ponto, recorramos a Eric Hobsbawn, segundo quem a divisão do trabalho na busca pelo acúmulo de capital persistia na exploração. Segundo o autor,

A situação do imediato pós-guerra em muitos países liberados e ocupados parecia solapar a posição dos políticos moderados [...]. Nessas circunstâncias, não surpreende que a aliança da época da guerra entre os grandes países capitalistas e o poder socialista agora à frente de sua própria zona de influência se tenha rompido, como muitas vezes acontece, no fim das guerras, até mesmo com coalizões menos heterogêneas. (HOBSBAWN, 1995, p. 228)

É possível notar a analogia entre o romance e o momento posterior à Primeira Guerra Mundial, no qual a sociedade se via diante de um quadro totalmente diferente do esperado. A situação "pós-guerra" do livro é o momento posterior à posse da fazenda pelos 
porcos, em que os outros animais paulatinamente passam a viver de acordo com a aliança pré-determinada por um líder que passa a concentrar de maneira absoluta o poder em suas mãos - grosso modo, portanto, o porco Napoleão faria as vezes de Joseph Stalin.

De acordo com Ernst Bloch, "o que importa é aprender a esperar. O ato de esperar não resigna: ele é apaixonado pelo êxito em lugar do fracasso [...] a ação desse afeto requer pessoas que se lancem ativamente naquilo que vai se tornando" (BLOCH, 2005, p. 13) ${ }^{1}$. O eventual fracasso, portanto, não deve borrar em definitivo o ímpeto: a distopia em que degringola o governo dos bichos (e o dos homens do contexto empírico) não deve negar a possibilidade e a necessidade da utopia. É confrontando os problemas e os fracassos do real que o horizonte utópico, afinal, se faz verdadeiramente desejável e necessário.

Ao contrário do que acontece com os animais no microcosmo da granja de Revolução dos Bichos, o boi Adão (João Adão ou João do Patrão) de Faẓenda Modelo, a "novela pecuária" de Chico Buarque, consegue perceber e articular sozinho sua insatisfação para com a exploração que é imposta a ele e ao resto do gado - ou seja, não é uma orientação vinda de fora (no romance de Orwell, o Velho Major) que sinaliza os caminhos da revolta. Embora Adão manifeste com maior contundência a insatisfação, o descontentamento é generalizado. O gado da obra de Buarque sente no couro a exploração, e não deixa de notála. O ímpeto revolucionário se reflete na vontade de falar sobre o que se nota de insatisfatório nos arredores, sobre o que aprisiona o corpo e a mente. O interesse não é outro senão propagar ideias contrárias às que são responsáveis por perpetuar a violência autoritária:

15 de julho. A Ariadna era uma que também não andava satisfeita. Era contra as coisas. Só que em vez de se conter, reclamava o troco e vomitava na roda-gigante. Pois ontem a junta médica resolveu examinar o seu caso. O tal Kamorra, assim que lhe perscrutou o abdome com o estetoscópio, fez uma cara nada boa. Alertou os colegas e todos concordaram com a cara ruim. Suspeitava-se que Ariadna

\footnotetext{
${ }^{1}$ Não nos escapa a ironia de recorrer a Bloch para discutir tais elementos da obra de Orwell. O ponto, contudo, escapa enormemente aos objetivos deste texto.
} 
estivesse utilizando indevidamente o seu cordão umbilical, cuja exclusiva função, como se sabe, é alimentar a criança no útero. Mas suspeitava-se que Ariadna, através desse cordão, estivesse passando mensagens negativas, perniciosas, infecciosas, capazes de desencaminhar a criança desde feto. Impressões deturpadas do nosso mundo exterior e, portanto, informações contrárias ao interesse geral, conforme boletim oficial da junta médica. Ontem Ariadna não voltou com o ônibus. Permaneceu no laboratório em observação. (BUARQUE, 1975, p 49)

Quando há insatisfação, ela é incontida, não respeita nenhum limite - e tal deslimite que é próprio das ideias que circulam livres é o que preocupa os mantenedores do status quo, acirrando a aplicação dos dispositivos de controle coercitivo. Os corpos podem ser presos, o couro do gado pode ser marcado pela brasa, mas as ideias são mais de mais difícil contenção: têm o hábito de almejar o horizonte utópico.

Como aqueles que conseguiram enxergar por trás do véu da propaganda estatal, no contexto do regime militar brasileiro em cujo seio Fazenda Modelo foi escrito e publicado, as personagens articulam criticamente as amarras que lhes privam da liberdade de ação e pensamento. Conseguem enxergar, em suma, as amarras que tentam lhes impedir a mera esperança, a possibilidade de formular a noção de um lugar melhor, uma utopia. Metonimicamente, na "novela pecuária" de Buarque, o gado é o povo brasileiro sob o jugo dos militares.

O poder é concedido ao Boi Juvenal por meio de um documento, uma possível referência ao Ato Institucional de 09 de Abril de 1964. Da mesma maneira, o autoritarismo de Juvenal pode ser percebido como símbolo do autoritarismo e repressão outorgados frente aqueles que ousassem se opuser ao governo da época. Nas palavras de Mary Elizabeth Ginway,

Nessa novela distópica, Buarque, cujas gravações musicais, peças e aparições foram sistematicamente censuradas durante a década de 1970 , encontra um novo veículo para protestar contra o regime. Como seu nome era bem conhecido, seu trabalho podia competir por um público leitor educado e de classe média que poderia de ou- 
tro modo ser cooptado pela televisão e por outras formas de entretenimento. A técnica do uso de alegoria permitiu a Buarque expressar suas frustações sobre as consequências da modernização e da repressão, sem se meter em dificuldades com a censura. $\mathrm{O}$ humor $\mathrm{e}$ o valor de choque da novela a tornam altamente agradável à leitura, e o fato de estar em sua décima quarta edição em 1997, disponível cerca de vinte e cinco anos após sua publicação original, é um testemunho da popularidade do seu autor e do poder da sua mensagem. (GINWAY, 2005, p. 103)

Assim como na obra de Orwell, as tensões entre esperança e frustração, utopia e distopia, se veem representadas literariamente por meio da figura do animal e do ambiente da fazenda. Representações distanciadas do quadro distópico em cujo seio surgem, transfigurações ficcionais de contextos autoritários de frustração.

O diálogo intertextual entre Faz̧enda Modelo e A Revolução dos Bichos também se estende à abordagem ficcional dos conflitos sociais resultantes das diferenças de classe do capitalismo. Eric Hobsbawn (1995) diz que a Revolução Russa "foi feita não para proporcionar liberdade e socialismo à Rússia, mas para trazer a revolução do proletariado mundial" (HOBSBAWN, 1995, p. 63). O romance de Orwell transfigura as atrocidades cometidas pela União Soviética no período em questão; a obra de Buarque, pelos militares na ditadura por eles capitaneada. Há o momento distópico em que se vive, e o utópico que se almeja; ambos são intrinsecamente ligados à representação literária do poder autoritário.

No âmbito formal, as obras são bastante distintas: Orwell adota uma prosa próxima de um registro tradicional; Buarque faz uso de diversos recursos pouco usuais, como o uso de ilustrações compostas de símbolos tipográficos e de mapas integrados à narrativa verbal. Como a forma necessariamente determina a maneira pela qual o conteúdo se vê veiculado e apreendido, no caso de Orwell o caráter fabular remete à procura e à sugestão de uma moral e de uma consequente analogia entre o ficcional e o empírico; no caso de Buarque, o choque provocado pelo caráter experimental pode retirar o leitor de sua zona de conforto e promover nele um novo olhar dos arredores.

Remetendo-nos ao clássico ensaio de Theodor W. Adorno, "Posição do narrador no romance contemporâneo", é por meio da imprevisibilidade da forma que Faz̧enda Modelo superaria a mera reprodução estática de um contexto de difícil apreensão. Valendo-se do 
choque, abdicando da tentativa de reproduzir o real de acordo com os parâmetros realistas instituídos na tradição literária, a obra de Buarque, de acordo com a leitura aqui proposta, realizaria o "esforço de capturar a essência, que por sua vez aparece como algo assustador e duplamente estranho no contexto do estranhamento cotidiano imposto pelas convenções sociais" (ADORNO, 2003, p. 58). Se a essência é a nossa natureza bovina, assustadora e estranha ela se revela...

Em A Revolução dos Bichos os animais buscam se distanciar do que os fazem parecidos com os humanos, como andar sobre duas pernas ou dormir em camas. Porém, os porcos pouco a pouco acabam se afastando desse acordo original feito entre os animais para que todos alcançassem felicidade e igualdade - e começam, os porcos, a ficar parecidos com os homens que antes os oprimiam. A utopia que se imaginava alcançada, que se imaginava enfim substituir a distopia, se converte em seu contrário, em uma nova distopia.

Como quer Bloch, a utopia é desejável como processo, esperança, horizonte a ser alcançado; quando é futuro desejável, é algo a ser buscado, é proposta de intervenção no que aflige no presente. Por outro lado, quando se quer completa, fechada e definitiva, já se converteu em algo diferente. Talvez, até, em algo radicalmente diferente: seu completo oposto, a odiosa distopia.

Assinalemos, novamente, que tais pontos são análogos em ambos os romances, mas ainda assim as obras são dotadas de autonomia e, portanto, particularidades. Os anseios utópicos e as ameaças distópicas não são os mesmos, dadas as diferenças expressivas e contextuais. Uma diferença a destacar é a que segue: em A Revolução dos Bichos, as personagens são diversos animais, mas em Faẓenda Modelo são apenas bovinos. Tal instância pode ser ilustrada pelos seguintes trechos:

Os primeiros foram os três cachorros [...] depois os porcos [...] As galinhas empoleiram-se nas janelas, as pombas voaram para os caibros do telhado, as ovelhas e as vacas deitaram-se atrás dos porcos e ali ficaram a ruminar. Os dois cavalos de tração chegaram juntos [...] Depois dos cavalos chegaram Maricota, a cabra branca, e Benjamin, o burro [...] uma ninhada patinhos órfãos [...] No último instante, Mimosa, a égua branca. (ORWELL, 2007, p. 10-11) 
Bois, vacas, bezerros andavam misturados (cerca não tinha) pelos alqueires. Ao todo éramos doze mil cabeças, ou cento e vinte, ou doze milhões, não sei, éramos muitas cabeças mas ninguém sabia o resultado do último censo. [...] Mas como ia dizendo, naquela transumância se desfaziam famílias e se constituíam outras. Se inventavam famílias como os bezerros Abá e Aurora que se apresentaram numa enxurrada dessas. (BUARQUE, 1974, p. 20 e 22)

Se no primeiro faz parte do projeto utópico o distanciamento da figura humana, no segundo as personagens agem e falam como humanos, reiterando contínua e intensamente o caráter metonímico: os bois são os próprios humanos durante o regime militar. Aos bois e aos humanos ficcionalmente transfigurados resta o horizonte utópico, como é só o que resta aos animais de $A$ Revolução dos Bichos em diversos momentos do romance. Acerca da comparação entre ambos, Ginway observa:

[Daphne Patai] defende que o final de Fazenda Modelo é mais otimista do que aquele de $A$ Revolução dos Bichos, porque o regime chega ao fim, mas isso é questionável porque o regime apenas muda o seu produto e não os seus métodos. Em geral, o desenvolvimento brasileiro continuou a seguir o modelo iniciado pelos militares, e Buarque também antecipa o fato de que os militares demoraram a abrir mão do poder, porque ele durou toda uma década após a publicação desse livro. (GINWAY, 2005, p. 99)

Desconfiada para com os rumos da Abertura Democrática, portanto, é a obra de Buarque. Trata-se de uma desconfiança infelizmente justificada, dada a preservação de dispositivos autoritários mesmo após o fim do regime militar ${ }^{2}$. A leitura aqui proposta, portanto, alinha-se à de Ginway: a conclusão do romance não parece alegremente "otimista", mas preocupada para com os rumos futuros do Brasil. Tal preocupação, destaquemos, não é uma negação da utopia, posto que, na visada de Bloch, a utopia nasce justamente a partir

2 Para uma leitura cuidadosa do ponto, ver o texto "Autoritarismo e Transição", de Paulo Sérgio Pinheiro. 
de um contato com os problemas do presente - e com os que se anunciam no futuro, é claro.

Aos bois, aos bichos, a esperança no horizonte utópico há de permanecer como algo a buscar, não presentificado. Observando a utopia desejada em cada obra, em cada contexto, é possível ver melhor tanto os anseios em pauta, quanto as insatisfações que a configuração distópica põe a claro. Põe a claro, inclusive, as eventuais deficiências do projeto utópico, as fissuras que acabam por fazer dele uma distopia.

Retornando aos elementos que assentam a leitura comparada, assinalemos novamente que Faz̧enda Modelo parte de uma perspectiva muito próxima à de $A$ Revolução dos Bichos: a utilização da alegoria com animais para uma possível denúncia de situação de abuso de poder. Observemos os trechos:

É preciso esclarecer desde já que, se uma série de incidentes desagradáveis arbitrariedades, atrocidades mesmo, passaram a ocorrer com freqüência a partir de sua gestão, Juvenal e sua bondade estiveram sempre alheios. Alguns de seus subordinados, delegados para o cumprimento de determinadas tarefas, certamente exorbitaram de suas atribuições (BUARQUE, 1974, p. 27).

Todo aquele ano, os bichos trabalhavam feito escravos. Mas trabalhavam felizes; não mediam esforço ou sacrifício, cientes de que tudo que fizessem reverteria em benefício deles próprios e de sua espécie [...] $\mathrm{Na}$ primavera e no verão, enfrentaram uma semana de sessenta horas de trabalho e em Agosto Napoleão fez saber que haveria trabalho também nos domingos à tarde (ORWELL, 2007, p. 52).

É como se o narrado não apenas transfigurasse ficcionalmente o contexto imediato, mas também colocasse em pauta os desejos idealizados de uma sociedade melhorada, uma utopia e, em seguida, o caminho que a poderia desmantelar rumo à distopia. É possível notar como cada obra lida, por meio de uma configuração ficcional específica, com as utopias e as distopias em pauta no seu momento histórico-social específico - e, mudando este, hão de mudar também as respectivas utopias e distopias. 
As noções de utopia e distopia, bem como suas abordagens ficcionais, necessariamente variam quando os tempos e os lugares também mudam. A Revolução dos Bichos e Faẓenda Modelo são um exemplo: diferentes anseios, medos e formas de elaborá-los ficcionalmente podem ser observados em cada uma das obras. De comum, contudo, a mesma simpatia pela liberdade de pensamento e o mesmo horror à configuração autoritária.

\title{
THE DISTOPYAN FARMS OF GEORGE ORWELL AND CHICO BUARQUE: FICTIONAL TRANSFIGURATIONS OF AUTHORITARIANISM
}

\begin{abstract}
The paper aims to discuss how the notions of utopia and dystopia are fictionally transfigured in different contexts, as well as the changes of these notions according to each time and place. The objects of the paper are two works of different moments and places: The Animal Farm, by George Orwell (1945), and Fazenda Modelo, by Chico Buarque (1976). In it, respectively, it is possible to perceive the allusion to the period of the Russian Revolution and to the dictatorial period in Brazil. The analysis also seeks to discuss the intertextual relation, addressing: the similar titles, the environments of animal exploration and the social criticism that lies at the heart of the discussion of both works in their utopian/dystopic imaginary frameworks. For such purpose, the theoretical basis will be provided by Ernst Bloch (2005), on the utopia, Eric Hobsbawn (1995), on the historical nature, and Mary Elizabeth Ginway (2005), on the comparative reading of the works in question.
\end{abstract}

KEYWORDS: Utopia; Dystopia; Animal Farm; Fazenda Modelo; Authoritarianism.

\section{REFERÊNCIAS}

ADORNO, Theodor W. Posição do narrador no romance contemporâneo. In Notas de literatura I. São Paulo: Ed 34, 2003.

BLOCH, Ernst. O Princípio Esperança. Vol. 1. Tradução de Nélio Schneider. Rio de Janeiro: EdUERJ: Contraponto, 2005.

BUARQUE, Chico. Faẓenda Modelo. São Paulo: Civilização Brasileira, 1976.

GINWAY, Mary Elizabeth. Fiç̧ão cientifica brasileira: mitos culturais e nacionalidade no país do futuro. Tradução de Roberto de Sousa Causo. São Paulo: Devir, 2005.

HOBSBAWM, Eric. A Era dos Extremos: O breve século XX: 1914-1991. Tradução de Marcos Santa Rita; Revisão técnica de Maria Célia Paoli. São Paulo: Companhia das Letras. 1995. 
ORWELL, George. A Revolução dos Bichos: um conto de fadas. Tradução de Heitor Aquino Ferreira; Posfácio de Christopher Hitchens. São Paulo: Companhia das Letras, 2007.

PINHEIRO, Paulo Sérgio. Autoritarismo e Transição. Revista USP. São Paulo, USP. n. 9, 1991

Recebido em: 31/05/2018. Aprovado em: 06/08/2018. 